\section{Two for the Price of One}

SIR,--You published an article (13 April, p. 113) on new hospital development under the title "Two for the Price of One." Some daily papers also derived this inference from a vague statement made by the Minister of Health at a press conference (1 April 1968) and from a booklet ${ }^{1}$ concerning two new hospital projects, in which it was stated that " the overall saving may amount to $40 \%$ or more." It can be affirmed categorically that, using the ordinary meaning of the term " hospital capital cost," it is impossible by any architectural method to cut the cost to that extent. The Ministry of Health has not achieved the impossible; but, starting with both the laudable aim of reasonable economy and by the exploitation of some more advanced thinking current in our profession on the future role of the district hospital, the Ministry has succeeded in altering the distribution of capital costs, some of which are transferred to other sectors to the benefit of the hospital's costing. A careful scrutiny of this wordy booklet is revealing.

In the assessment of needs of acute beds for a population of 170,000 on the traditional figure of three beds per thousand people some 540 beds would be required. The project team reckoned that by using a policy of high efficiency of administration and of admissions and discharges, by the integration of community care and aftercare within the hospital, by the extended use of "day surgery," and by the fuller use of outpatient investigation (often a questionable policy) it would be feasible to reduce the acute beds to 340 - that is, at the rate of two beds per 1,000 population. Thus with one blow a $33 \%$ cut is made in the major inpatient provision. The increased cost of the community services so involved is of course on another account, and the extra cost of staff (doctors and nurses) required when the degree of "nursing dependency" is heightened goes to annual expenditure. The suggestion, too, that supplementary peripheral outpatient clinics will be required postpones allocation of capital to a later date. Provision is made for only 50 geriatric beds (acute and assessment), and the rest are to be housed in upgraded existing accommodation, and the cost of upgrading will appear in another balance-sheet, while modern views of geriatric care are ignored. Other similar operations reduce the capital costs: firstly by iimiting residential building to trainee nurses and essential medical and other staff, relying on the local housing authority's allocation of available accommodation, and secondly by providing some of the industrial zone functions such as laundry, workshops, and the central sterilizing supply department off the site.

The description of the architectural features designed to cut costs also tends to mislead. Such flat sites with adjacent wellserviced roads do not represent average conditions. There is no scale on the sketch plans, and the reader must estimate the dimensions; the Architects' fournal ${ }^{2}$ filled in some helpful details. It is clear that standards have been lowered. The wards have only $11 \%$ of single beds, which are unfunctionally distributed; the other patients are in six and eight open bays (with small day spaces) of approximately 550 sq. ft. (51 sq. m.). Clerestory lighting is used, which can produce cold downdraugnts in the wards beneath, treatment rooms are very distant from the wards, and the traffic in lengthy communication corridors is mixed with motorized floats. The claim of flexibility in ward use reveals the planners' ignorance of the significance of the Falkirk ward. ${ }^{3}$

The hospitals occupy over five acres each, and are built on two floors with only two lifts and a service ramp. The departments most likely to grow, pathology and radiology, are closely hemmed in and have only a derisory possibility of expansion-the hallmark of poor planning. It is even suggested that if the pathology department gets overloaded some of the work could be moved elsewhere, and the idea of changing the user of this mostly expensively serviced department is viewed with equanimity. The entrance concourse, with its snack bar for everybody, shop, bank, and registration office, carries the outpatient traffic and all the two-way traffic of the dispensary, $x$-ray, and pathology departments and breaks every traffic rule. The records office is separated from the outpatients department by the emergency and accident department, and the approach from the hospital to the physiotherapy area looks unsatisfactory in the sketch.

These low-rise buildings absolutely squander land-the Ministry ignores this. The majority of urban sites are not so extensible, and the Ministry's policy on on-costs is as shortsighted as it is wasteful in its inevitably excessive site-coverage. A notable omission is any mention of the increase of porters required for such hospitals.

Whatever may be one's personal views of the relative importance of the priorities of public expenditure, it is regrettable that the Ministry should describe so much false economy in such misleading terms.-I am, etc.,

London N.W.8. HUGH Gainsborough.

REFERENCES
1 Rationalization of Planning and Design, 1968.
Ministry of Health.
2 Architects' fournal, 1968, 10 April, p. 721.
${ }^{3}$ Brit. med. F., 1966, 2, 1195.

2 Architects' fournal, 1968, 10
${ }_{3}^{3}$ Brit. med. F., 1966, 2, 1195.

\section{Assessing “Clinical Competence”}

SIR,- “ Trained examiners or professional actors have been used to play the part of patients to test the history-taking ability ..." I am all for a leavening of wit in medical writing, and, coming across these words in a recent leading article of yours (27 April, p. 188), I was all set to join in the chuckle until I continued, ". . . but many examiners feel that such devices are far removed from the real clinical situation," and received the uncomfortable impression that whether the B.M.F. approved or disapproved they were, incredibly, taking this nonsense seriously. My faith in the medical profession as one of the few scientific bodies who had not been seduced by the "technological revolution" but had retained some respect for the human being was further shaken by another statement in the article: "The student types in his request for data and the computer provides the appropriate response. Such dialogues between students and computer may well be found to be increasingly valuable in the future."

Whatever next? A new generation of students prodding plastic tummies and analysing artificial urine? Are we going to let the profession's technomaniacs get away with the pretence that medicine is an intellectual game to be played with fake patients in fake situations, or that we can learn clinical medicine by carrying on typewritten conversations with a sickly computer?

A few years ago that leading article could have found itself in print only as a satirical endpiece. Perhaps it was a belated "April fool." For everyone's sake, I sincerely hope so.-I am, etc.,

$$
\begin{aligned}
& \text { Medical Research Council, J. C. Bignall. } \\
& \text { Pneumoconiosis Research Unit, } \\
& \text { Llandough Hospital, } \\
& \text { Penarth, Glamorgan. }
\end{aligned}
$$

\section{Deaths from Asthma}

SIR,-It is with interest and a good deal of disappointment that I have followed your leading article (10 February, p. 329), the excellent articles referred to therein (pp. 335, 339 ), and the subsequent correspondence. Here in this country we can only agree with your statistics about the disturbing increase in the death rate from bronchial asthma. It is from careful studies such as the two referred to in your leading article that we hope to find out the cause of this alarming increase and then to try to eradicate it by good preventive medicine.

It is, however, with astonishment that I note a complete absence of mention of the role of allergic factors in the causation of asthma, be it ingestants or inhalants, and what we can do to overcome this through avoidance and appropriate hyposensitization. With my great affection and respect for British medicine I fail to understand the complete lack of interest in this important field and the poten:irl benefit that asthmatic patients are liable to receive from a carefully controlled anti-aï:rgy management consisting of avoidance and possible hyposensitization. Any effective tool can be misused and mishandled, but the occasional abuse of hyposensitization in untrained hands makes the result we obtain in clinical practice no less spectacular.

In the article "Investigation Into Use of Drugs Preceding Deaths from Asthma" (p. 339) I am astonished by the brief and cursory reference to theophylline and aminophylline intake prior to the death of these patients. In this country we consider aminophylline or its derivatives as one of the major iatrogenic causes of death in the asthmatic patient. Aminophylline is capable of causing either sudden death or severe and frequently fatal toxic involvement of the cardiovascular system, the central nervous system, or the gastrointestinal tract. Investigation into the intake of this drug, either in combination with other bronchodilators or on its own, is worthy of a great deal of consideration. So far as corticosteroids and pressurized aerosols are concerned, we certainly agree with our British colleagues, except that we would like to be more conservative in the use of corticosteroids. We most emphatically endorse your leading article that "sedatives are absolutely contraindicated in acute asthma." The 